\title{
Perbandingan Angka Ketahanan Hidup Penderita Kanker Ovarium yang Mendapat Terapi Regimen Kemoterapi Paclitaxel-Carboplatin dan Cyclophosphamide- Adiamycin-Cisplatin di RSUP Dr.Sardjito: Studi retrospektif Januari 2014- Desember 2018
}

\author{
Choery Novitasari ${ }^{1}$, Ahsanuddin Attamimi ${ }^{2}$, Heru Pradjatmo ${ }^{3}$ \\ 1,2,3 Departemen Obstetri dan Ginekologi, \\ Fakultas Kedokteran, Kesehatan Masyarakat dan Keperawatan, Universitas Gadjah Mada \\ Korespondensi: ${ }^{1}$ choery.novitasari@yahoo.com
}

Submisi: 18 Juni 2020; Revisi: 28 Agustus 2020; Penerimaan: 7 September 2020

\begin{abstract}
Background: Cancer has high mortality rates and is the leading cause of mortal diseases, just second to cardiovascular diseases. Seventy percent of cancer occurs in developing countries. Ovarian cancer is ninth most prevalence cancer in woman and fifth in mortality rates, around 8.6 in 100,000. There are 21,880 new cases and 13.850 death from ovarian cancer in United States every year.

Objective: This study compare the survival rates between group of patient which treated with Paclitaxel-Carboplatin (PC) Chemotherapy Regiments and Cyclophosphamide-Adriamycin-Cisplatin (CAP) Regiments in Sardjito General Hospital.

Method: Retrospective study was done by collecting data from medical records. Subjects divided into two groups based on their chemotherapy regiments and survival analysis conducted between groups.

Result and Discussion: There were 353 ovarian cancer patients treated with chemotherapy regiments, divided into 265 patients treated with PC and 88 patients treated with CAP. Bivariate analysis showed that chemotherapy PC and CAP regimens did not affect survival rates ( $H R=1.15, \quad p=0.64$, $\mathrm{C} \mid 95 \%=0.64-2.05)$. Age $<50$ years old $(\mathrm{HR}=0.42, \mathrm{p}=0.01, \mathrm{Cl} 95 \%=0.23-0.77)$, early clinical stage $(\mathrm{HR}=0.27, \quad \mathrm{p}=0.00, \quad \mathrm{C} \mid 95 \%=0.14-0.49)$, andCA125 after chemotherapy $<70 \mathrm{U} / \mathrm{mL}(\mathrm{HR}=0.21, \mathrm{p}=0.00, \quad \mathrm{Cl} 95 \%=0.11-0.41)$ are prognostic factors for better survival rates in patients with ovarian cancer. Multivariate analysis with survival rates (cox's regression) showed that factors influencing survival rates were early clinical stage (HR=0.45, $p=0.04$, $\mathrm{Cl} 95 \%=0.18-0.91)$ and $\mathrm{CA} 125$ after chemotherapy $<70 \mathrm{U} / \mathrm{mL}(\mathrm{HR}=0.33, \mathrm{p}=0.01, \mathrm{Cl} 95 \%=0.15-0.74)$.

Conclusion: There is no significant difference between chemotherapy regiment PC and CAP with survival rate of the ovarian cancer patients treated in RSUP dr. Sardjito for 2014- 2018. Factors influencing better survival rates of the ovarian cancer patients are early clinical stage and CA125 after chemotherapy $>70 \mathrm{U} / \mathrm{mL}$.
\end{abstract}

Keywords: Survival rate; ovarian cancer; Paclitaxel-Carboplatin regiment; Cyclophosphamide-Adriamycin Cisplatin regiment

\begin{abstract}
ABSTRAK
Latar Belakang: Kanker merupakan penyebab kematian kedua terbanyak setelah penyakit kardiovaskular dan lebih dari $70 \%$ kematian yang disebabkan oleh kanker terjadi di negara berkembang. Kanker ovarium merupakan kanker terbanyak kesembilan pada wanita dan menjadi kanker dengan mortalitas ke-5 terbanyak, yaitu 8,6 per 100.000 .

Tujuan: Menilai angka ketahanan hidup penderita kanker ovarium yang diberikan kemoterapi dengan regimen Paclitaxel- Carboplatin dibandingkan dengan regimen Cyclophospamide-Adriamicyn-Cisplatin di RSUP Sardjito.

Metode: Penelitian ini merupakan penelitian observasional dengan rancangan studi analisis angka ketahanan hidup (survival rate) dari penderita kanker ovarium. Data akan diambil secara retrospektif dari rekam medis pasien kanker ovarium yang berobat ke RSUP dr. Sardjito kemudian ditelusuri riwayat kematiannya.

Hasil dan Pembahasan: Terdapat 353 penderita kanker ovarium yang dilakukan kemoterapi, terdiri dari 265 subjek yang diterapi PC dan 88 subjek yang diterapi dengan CAP. Dari analisis bivariat didapatkan bahwa regimen kemoterapi PC dan CAP tidak memengaruhi angka ketahanan hidup (HR=1,15, $\mathrm{p}=0,64, \mathrm{Cl} 95 \%=0,64-2,05)$. Usia $<50$ tahun ( $\mathrm{HR}=0,42, \mathrm{p}=0,01, \mathrm{Cl} 95 \%=0,23-0,77)$, stadium klinis awal $(\mathrm{HR}=0,27, \mathrm{p}=0,00, \mathrm{Cl} 95 \%=0,14-0,49)$, dan $\mathrm{CA} 125$ pasca kemoterapi $<70 \mathrm{U} / \mathrm{mL}(\mathrm{HR}=0,21, \quad \mathrm{p}=0,00, \quad \mathrm{Cl} 195 \%=0,11-0,41)$ merupakan faktor protektif terhadap angka ketahanan hidup penderita kanker ovarium. Analisis multivariat dengan angka ketahanan hidup (cox's regression) menunjukkan bahwa faktor yang dapat meningkatkan angka ketahanan hidup adalah stadium klinis awal ( $H R=0,45, \quad p=0,04, C l 95 \%=0,18-0,91)$ dan CA125 pasca kemoterapi (HR=0,33, $p=0,01, C l 95 \%=0,15-0,74)$.
\end{abstract}


Kesimpulan: Tidak ada perbedaan bermakna antara regimen kemoterapi PC dan CAP dengan angka ketahanan hidup penderita kanker ovarium yang dirawat di RSUP dr. Sardjito selama tahun 2014-2018. Faktor- faktor yang dapat meningkatkan angka ketahanan hidup pasien kanker ovarium adalah stadium klinis awal dan CA125 pasca kemoterapi $<70 \mathrm{U} / \mathrm{mL}$.

Kata kunci: Angka ketahanan hidup; kanker ovarium; regimen paclitaxel dan carboplatin; regimen cyclophosphamide, adriamycin, cisplatin

\section{PENDAHULUAN}

Kanker ovarium merupakan kanker terbanyak kesembilan pada wanita $^{1}$ dan menjadi kanker dengan mortalitas ke 5 terbanyak, yaitu 8,6 per 100.000. Studi memperkirakan bahwa terdapat sekitar 21.880 kasus baru dan 13.850 kematian di Amerika setiap tahunnya. ${ }^{2}$ Sekitar 1 dari 71 wanita diperkirakan berisiko untuk menderita kanker ovarium yang invasif sepanjang masa hidupnya dan sekitar 1 dari 95 wanita meninggal dikarenakan kanker ovarium invasif tersebut. ${ }^{1}$

Angka kejadian kanker ovarium yang cukup tinggi mendorong dilakukannya berbagai studi untuk mengetahui keefektifan modal terapi. Modal terapi kanker secara garis besar dapat dibedakan menjadi terapi bedah, terapi radiasi, kemoterapi dan imunoterapi. Perkembangan dalam metode terapi kanker telah meningkatkan angka ketahanan hidup penderita kanker secara signifikan. ${ }^{3}$

Prinsip terapi kanker ovarium pada dasarnya adalah dengan melakukan total abdominal histerektomi pada kanker ovarium stadium 1A hingga stadium $1 C$. Pasien kanker ovarium stadium II, III, dan IV dilakukan bedah sitoreduksi atau dengan pemberian neoadjuvan kemoterapi. ${ }^{4}$

Kemoterapi dapat diberikan dengan berbagai regimen. Regimen kemoterapi yang digunakan di RSUP Dr. Sardjito saat ini adalah paclitaxel (golongan taxane) dan carboplatin (golongan platinum) serta regimen cyclophospamide, adriamicyn, dan cisplatin. ${ }^{5}$ Regimen kemoterapi yang diberikan dapat berhubungan dengan ketahanan hidup dari penderita kanker ovarium.

Kemoterapi dengan regimen paclitaxelcarboplatin digunakan sebagai terapi kuratif pada kanker ovarium stadium I,II, dan III, kanker peritoneal primer, dan kanker tuba falopi. Regimen ini digunakan sebagai regimen kemoterapi lini pertama post operasi untuk kanker ovarium epitel stadium II, III, dan IV yang baru pertama kali terdiagnosis. Efek samping yang paling sering terjadi pada pemberian regimen ini adalah mialgia, arthralgia, neuropati perifer, mielosupresi, mual, muntah, dan reaksi hipersensitivitas. ${ }^{6}$

Kemoterapi dengan regimen cyclophosphamideadriamycin-cisplatin digunakan sebagai terapi kanker ovarium pada pasien yang tidak dapat mentolerir terapi dengan paclitaxel. Efek samping yang paling sering terjadi dari penggunaan regimen ini adalah mual dan muntah, nefrotoksisitaas, neurotoksisitas, ototoksisitas, myelosupresi, sistitis, dan fatique. Penggunaan regimen paclitaxelcarboplatin lebih superior dibandingkan dengan cyclophosphamide-cisplatin pada kanker ovarium stadium lanjut. ${ }^{6}$ Hingga saat ini belum terdapat data angka ketahanan hidup penderita kanker ovarium yang dibedakan berdasarkan regimen kemoterapi yang diberikan di Indonesia, khususnya di RSUP Dr. Sardjito, Yogyakarta. Oleh karena itu, penelitian ini dilakukan supaya dapat memberikan gambaran mengenai angka ketahanan hidup penderita kanker ovarium di RSUP Dr. Sardjito berdasarkan regimen kemoterapi yang diterima oleh pasien.

\section{METODE}

Penelitian ini merupakan penelitian observasional dengan rancangan studi analisis angka ketahanan hidup (survival rate) dari penderita kanker ovarium. Data akan diambil secara retrospektif dari rekam medis pasien kanker ovarium yang berobat ke RSUP dr. Sardjito kemudian ditelusuri riwayat kematiannya. 
Subjek penelitian adalah penderita yang didiagnosis kanker ovarium pertama kali pada periode Januari tahun 2014 sampai dengan bulan Desember tahun 2018 yang datang memeriksakan diri di bagian ilmu obstetri dan ginekologi RSUP Dr. Sardjito serta memenuhi kriteria inklusi dan eksklusi.

Kriteria inklusi adalah penderita telah didiagnosis kanker ovarium secara pasti secara histopatologis, telah menjalani kemoterapi dengan regimen Paclitaxel-Carboplatin atau regimen Cyclophosphamide-Adriamycin- Cisplatin selama minimal 1 siklus. Kriteria eksklusi adalah penderita kanker ovarium yang sebab kematiannya bukan dikarenakan kanker ovarium, menderita kanker lainnya, dan rekam medis tidak lengkap.

\section{HASIL DAN PEMBAHASAN}

Subjek penelitian ini sebanyak 353 pasien kanker ovarium. Tabel 1 menunjukkan sebaran pasien kanker ovarium yang mendapatkan regimen kemoterapi PC sebanyak $75,1 \%$ sedangkan pasien kanker ovarium yang mendapatkan regimen kemoerapi CAP sebanyak 24,9\%. Sebaran pasien dengan usia kurang dari 50 tahun adalah 39,0\% sedangkan usia 50 tahun atau lebih adalah $61,0 \%$. Sebaran pasien dengan jumlah paritas 0 adalah $32,3 \%$ sedangkan pasien dengan jumlah paritas $\geq 1$ adalah $67,7 \%$. Sebaran pasien dengan indeks massa tubuh $<25 \mathrm{~kg} / \mathrm{m} 2$ adalah $71,1 \%$ dan indeks massa tubuh $\geq 25 \mathrm{~kg} / \mathrm{m} 2$ sebesar $28,9 \%$.

Berdasarkan stadium klinis, sebaran pasien yang berada pada stadium awal (I-II) adalah sebesar $45 \%$ dan stadium lanjut (III-IV) adalah sebesar $55 \%$. Berdasarkan histopatologi, sebaran pasien didominasi oleh epitel tipe I sebesar $64,2 \%$, diikuti oleh epitel tipe II sebesar 35,8\%. Pasien kanker ovarium dengan histopatologi derajat diferensiasi baik sebesar 22,7 dan diferensiasi sedang-buruk sebesar $77,3 \%$. Nilai CA125 pasca kemoterapi<70 U/
$\mathrm{mL}$ sebesar $85,2 \%$ dan $\geq 70 \mathrm{U} / \mathrm{mL}$ sebesar $\quad 14,8 \%$. Pasien yang mendapatkan tindakan operasi optimal sebesar $65,0 \%$ sedangkan yang tidak optimal sebesar $35,0 \%$.

Tabel 1. Distribusi Frekuensi Pasien Kanker Ovarium

\begin{tabular}{|c|c|c|}
\hline \multirow{2}{*}{ Variabel } & \multicolumn{2}{|c|}{ Distribusi dan Frekuensi } \\
\hline & $\mathbf{N}$ & $\%$ \\
\hline \multicolumn{3}{|c|}{ Regimen Kemoterapi } \\
\hline PC & 265 & 75,1 \\
\hline CAP & 88 & 24,9 \\
\hline \multicolumn{3}{|l|}{ Usia } \\
\hline$<50$ tahun & 133 & 39,0 \\
\hline$\geq 50$ tahun & 208 & 61,0 \\
\hline \multicolumn{3}{|l|}{ Paritas } \\
\hline 0 & 112 & 32,3 \\
\hline$\geq 1$ & 235 & 67,7 \\
\hline \multicolumn{3}{|c|}{ Indeks massa tubuh } \\
\hline$<25 \mathrm{~kg} / \mathrm{m} 2$ & 246 & \\
\hline$\geq 25 \mathrm{~kg} / \mathrm{m} 2$ & 100 & \\
\hline \multicolumn{3}{|l|}{ Stadium klinis } \\
\hline Awal & 150 & 45,0 \\
\hline Lanjut & 183 & 55,0 \\
\hline \multicolumn{3}{|l|}{ Histopatologi } \\
\hline Epitel tipe I & 221 & 64,2 \\
\hline Epitel tipe II & 123 & 35,8 \\
\hline \multicolumn{3}{|c|}{ Derajat diferensiasi } \\
\hline Baik & 27 & 22,7 \\
\hline Sedang-buruk & 92 & 77,3 \\
\hline \multicolumn{3}{|c|}{ Nilai CA125 (U/mL) } \\
\hline$<70$ & 207 & 85,2 \\
\hline$\geq 70$ & 36 & 14,8 \\
\hline \multicolumn{3}{|c|}{ Optimalisasi tindakan } \\
\hline Optimal & 225 & 63,7 \\
\hline Tidak Optimal & 128 & 36,3 \\
\hline
\end{tabular}

$* p<0,05$

Hasil analisis bivariat disajikan pada tabel 2 . 
Tabel 2. Analisis Bivariat

\begin{tabular}{|c|c|c|c|c|c|c|c|}
\hline \multirow{3}{*}{ Variabel } & \multicolumn{4}{|c|}{ Status Hidup } & \multirow{3}{*}{ HR } & \multirow{3}{*}{ Cl 95\% } & \multirow{3}{*}{$\mathbf{p}$} \\
\hline & \multicolumn{2}{|c|}{ Meninggal } & \multicolumn{2}{|c|}{ Hidup } & & & \\
\hline & $\mathbf{N}$ & $\%$ & $\mathbf{N}$ & $\%$ & & & \\
\hline \multicolumn{8}{|l|}{ Regimen } \\
\hline PC & 47 & 17,7 & 218 & 82,3 & 1,15 & $0,64-2,05$ & 0,64 \\
\hline CAP & 15 & 17,0 & 73 & 83,0 & & & \\
\hline \multicolumn{8}{|l|}{ Usia } \\
\hline$<50$ tahun & 14 & 10,5 & 119 & 89,5 & 0,42 & $0,23-0,77$ & $0,01^{*}$ \\
\hline$\geq 50$ tahun & 43 & 20,7 & 165 & 79,3 & & & \\
\hline \multicolumn{8}{|l|}{ Paritas } \\
\hline 0 & 23 & 20,5 & 89 & 79,5 & 1,18 & $0,70-1,98$ & 0,54 \\
\hline$\geq 1$ & 39 & 16,6 & 196 & 83,4 & & & \\
\hline \multicolumn{8}{|c|}{ Indeks Massa Tubuh } \\
\hline$<25 \mathrm{~kg} / \mathrm{m} 2$ & 43 & 17,5 & 203 & 82,5 & 1,09 & $0,63-1,89$ & 0,76 \\
\hline$\geq 25 \mathrm{~kg} / \mathrm{m} 2$ & 18 & 18,0 & 82 & 82,0 & & & \\
\hline \multicolumn{8}{|l|}{ Stadium Klinis } \\
\hline Awal & 13 & 8,7 & 137 & 91,3 & 0,27 & $0,14-0,49$ & $0,00 *$ \\
\hline Lanjut & 45 & 24,6 & 138 & 75,4 & & & \\
\hline \multicolumn{8}{|l|}{ Histopatologi } \\
\hline Epitel tipe I & 38 & 17,2 & 183 & 82,8 & 0,85 & $0,51-1,43$ & 0,54 \\
\hline Epitel tipe II & 23 & 18,7 & 100 & 81,3 & & & \\
\hline \multicolumn{8}{|c|}{ Derajat Diferensiasi } \\
\hline Baik & 2 & 7,4 & 25 & 92,6 & 0,31 & $0,07-1,34$ & 0,12 \\
\hline Sedang-buruk & 23 & 25,0 & 69 & 75,0 & & & \\
\hline \multicolumn{8}{|c|}{ Nilai CA125 (U/mL) } \\
\hline$<70$ & 24 & 11,6 & 183 & 88,4 & 0,21 & $0,11-0,41$ & $0,00 *$ \\
\hline$\geq 70$ & 14 & 38,9 & 22 & 61,1 & & & \\
\hline \multicolumn{8}{|c|}{ Optimalisasi Tindakan } \\
\hline Optimal Tidak & 37 & 16,4 & 188 & 83,6 & 0,91 & $0,55-1,51$ & 0,71 \\
\hline Optimal & 25 & 19,5 & 103 & 80,8 & & & \\
\hline
\end{tabular}

$*_{p}<0,05$

Masing-masing variabel dinyatakan bermakna signifikan terhadap angka ketahanan hidup apabila $p<0,05$. Nilai HR (hazard ratio) lebih dari 1 berarti bahwa variabel bermakna secara statistik berisiko meningkatkan angka kematian pada penderita kanker ovarium. Hasil penelitian menunjukkan bahwa tidak terdapat perbedaan bermakna antara regimen kemoterapi PC dan CAP dengan status survival penderita kanker ovarium. Terdapat perbedaan bermakna antara usia, stadium klinis, dan nilai CA125 pasca kemoterapi dengan status survival penderita kanker ovarium, $p<0,05$. Ketiga variabel 
tersebut merupakan variabel perancu. Variabel perancu lain seperti paritas, indeks massa tubuh, histopatologi, derajat diferensiasi, dan optimalisasi tindakan secara statistik tidak memengaruhi status survival penderita kanker ovarium.

Survival penderita kanker ovarium yang diterapi dengan PC dan CAP dapat dilihat pada tabel 3. Ratarata lama hidup pasien kanker ovarium dengan regimen kemoterapi PC adalah 48,92 bulan dengan $\mathrm{Cl} 95 \%(44,91-52,92)$ bulan namun pasien kanker ovarium dengan regimen kemoterapi CAP adalah 49,64 bulan dengan $\mathrm{Cl} 95 \%(44,04-55,23)$ bulan.

Tabel 3. Tabel Harapan Hidup Pasien Kanker Ovarium

\begin{tabular}{lcccc} 
Regimen & Estimasi & Std. Error & \multicolumn{2}{c}{ Cl 95\% } \\
\cline { 4 - 5 } Kemoterapi & (bulan) & Batas Bawah & Batas Atas \\
\hline PC & 48,92 & 2,04 & 44,91 & 52,92 \\
CAP & 49,64 & 2,86 & 44,04 & 55,23 \\
\hline
\end{tabular}

Kurva harapan hidup pasien dengan regimen kemoterapi PC dan CAP dapat ditunjukkan pada kurva Kaplan Meier gambar 1.

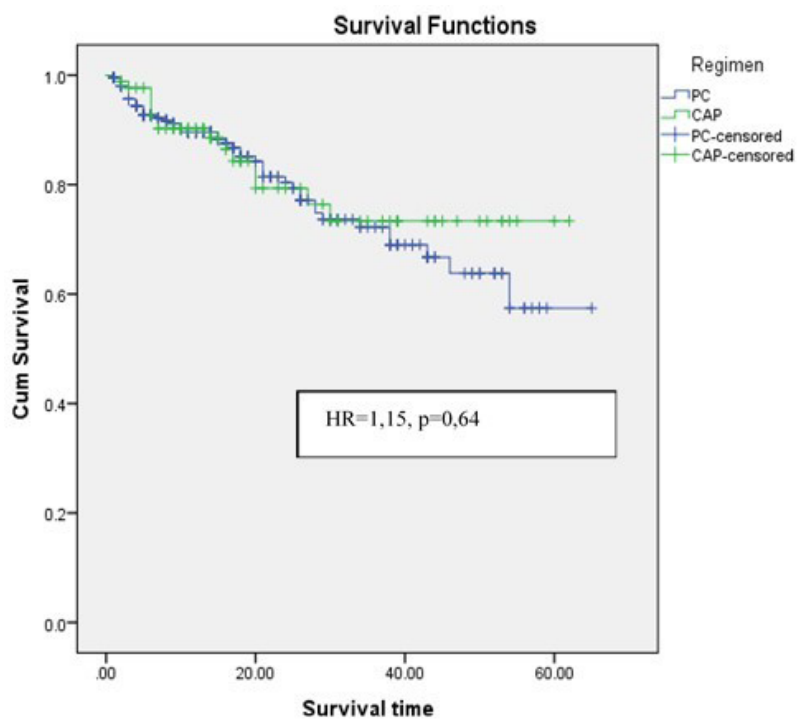

Gambar 1. Kurva Harapan Hidup Pasien berdasarkan Regimen Kemoterapi

Penderita kanker ovarium yang diterapi dengan PC memiliki risiko kematian sebesar 1,15 kali dibandingkan dengan penderita kanker ovarium yang diterapi dengan CAP, dengan nilai $\mathrm{p} 0,64$.
Hubungan survival penderita kanker ovarium di RSUP dr. Sardjito dengan kelompok variabel didapatkan bahwa usia, stadium klinis, nilai CA125 pasca kemoterapi secara statistik memengaruhi angka ketahanan hidup dengan $p<0,05$. Variabelvariabel yang memiliki nilai $p<0,25$ dilanjutkan untuk analisis multivariat. Variabel-variabel tersebut adalah usia, stadium klinis, nilai CA125 pasca kemoterapi, dan derajat diferensiasi. Akan tetapi, variabel-variabel lain tetap dimasukkan ke analisis multivariat karena menurut studi literatur, variabel tersebut dapat memengaruhi angka ketahanan hidup.

Berdasarkan uji multivariat yang ditunjukkan pada tabel 4, variabel yang berpengaruh terhadap angka ketahanan hidup adalah stadium dan CA125 pasca kemoterapi. Pasien dengan stadium awal memiliki risiko kematian sebesar 0,45 kali dibandingkan dengan stadium lanjut. Pasien dengan CA125 pasca kemoterapi $<70 \mathrm{U} / \mathrm{mL}$ memiliki risiko kematian sebesar 0,33 kali dibandingkan dengan CA125 $\geq 70 \mathrm{U} / \mathrm{mL}$. 
Tabel 4. Uji Multivariat terhadap Angka Ketahanan Hidup (Cox's Regression)

\begin{tabular}{|c|c|c|c|c|c|c|c|}
\hline \multirow{3}{*}{ Variabel } & \multicolumn{4}{|c|}{ Status Hidup } & \multirow{3}{*}{ HR } & \multirow{3}{*}{$\mathrm{Cl} 95 \%$} & \multirow{3}{*}{$\mathbf{p}$} \\
\hline & \multicolumn{2}{|c|}{ Meninggal } & \multicolumn{2}{|c|}{ Hidup } & & & \\
\hline & $\mathbf{N}$ & $\%$ & $\mathbf{N}$ & $\%$ & & & \\
\hline \multicolumn{8}{|l|}{ Regimen } \\
\hline PC & 47 & 17,7 & 218 & 82,3 & 1,15 & $0,64-2,05$ & 0,64 \\
\hline CAP & 15 & 17,0 & 73 & 83,0 & & & \\
\hline \multicolumn{8}{|l|}{ Usia } \\
\hline$<50$ tahun & 14 & 10,5 & 119 & 89,5 & 0,42 & $0,23-0,77$ & $0,01 *$ \\
\hline$\geq 50$ tahun & 43 & 20,7 & 165 & 79,3 & & & \\
\hline \multicolumn{8}{|l|}{ Paritas } \\
\hline 0 & 23 & 20,5 & 89 & 79,5 & 1,18 & $0,70-1,98$ & 0,54 \\
\hline$\geq 1$ & 39 & 16,6 & 196 & 83,4 & & & \\
\hline \multicolumn{8}{|c|}{ Indeks Massa Tubuh } \\
\hline$<25 \mathrm{~kg} / \mathrm{m} 2$ & 43 & 17,5 & 203 & 82,5 & 1,09 & $0,63-1,89$ & 0,76 \\
\hline$\geq 25 \mathrm{~kg} / \mathrm{m} 2$ & 18 & 18,0 & 82 & 82,0 & & & \\
\hline \multicolumn{8}{|l|}{ Stadium Klinis } \\
\hline Awal & 13 & 8,7 & 137 & 91,3 & 0,27 & $0,14-0,49$ & $0,00 *$ \\
\hline Lanjut & 45 & 24,6 & 138 & 75,4 & & & \\
\hline \multicolumn{8}{|l|}{ Histopatologi } \\
\hline Epitel tipe I & 38 & 17,2 & 183 & 82,8 & 0,85 & $0,51-1,43$ & 0,54 \\
\hline Epitel tipe II & 23 & 18,7 & 100 & 81,3 & & & \\
\hline \multicolumn{8}{|c|}{ Derajat Diferensiasi } \\
\hline Baik & 2 & 7,4 & 25 & 92,6 & 0,31 & $0,07-1,34$ & 0,12 \\
\hline Sedang-buruk & 23 & 25,0 & 69 & 75,0 & & & \\
\hline \multicolumn{8}{|c|}{ Nilai CA125 (U/mL) } \\
\hline$<70$ & 24 & 11,6 & 183 & 88,4 & 0,21 & $0,11-0,41$ & $0,00^{*}$ \\
\hline$\geq 70$ & 14 & 38,9 & 22 & 61,1 & & & \\
\hline \multicolumn{8}{|c|}{ Optimalisasi Tindakan } \\
\hline Optimal Tidak & 37 & 16,4 & 188 & 83,6 & 0,91 & $0,55-1,51$ & 0,71 \\
\hline Optimal & 25 & 19,5 & 103 & 80,8 & & & \\
\hline
\end{tabular}

$* p<0,05$

\section{HASIL DAN PEMBAHASAN}

Pengobatan kanker ovarium masih menjadi sebuah tantangan. Operasi debulking primer dan sitoreduksi diikuti dengan kemoterapi primer masih menjadi pengobatan utama untuk kanker ovarium stadium lanjut. Hingga saat ini, kemoterapi lini pertama yang standar adalah paclitaxel dengan tambahan carboplatin. ${ }^{7}$ Walaupun respon awal terhadap terapi sistemik baik setelah operasi debulking optimal, angka ketahanan hidup jangka panjang masih rendah, dengan rekurensi risiko tinggi8. Pengobatan kanker ovarium memengaruhi kualitas hidup akibat munculnya efek samping kemoterapi seperti alopesia, neurotoksisitas, dan kelelahan. ${ }^{8}$ Dalam rangka mencapai efikasi dan menurunkan toksisitas dari kemoterapi lini pertama, beberapa alternative pengobatan sedang dalam investigasi. ${ }^{8}$ Penelitian kami membandingkan antara paclitaxel-carboplatin (PC) dan cyclophosphamideadriamycin-cisplatin (CAP). Penggunaan regimen kemoterapi untuk penderita kanker ovarium telah menjadi materi studi selama bertahun-tahun. Penggunaan paclitaxel yang dikombinasikan dengan 
cisplatin terbukti lebih baik jika dibandingkan dengan kombinasi cyclophosphamide dan cisplatin dalam hal laju respon, perhentian progresi kanker, dan angka ketahanan hidup secara keseluruhan.

Hasil penelitian kami menunjukkan bahwa tidak ada perbedaan bermakna antara regimen kemoterapi PC dan CAP terhadap angka ketahanan hidup pada penderita kanker ovarium yang dirawat di RSUP dr. Sardjito dari tahun 2014-2018. Hasil ini sejalan dengan studi yang dilakukan oleh The International Collaborative Ovarian Neoplasm Study (ICON)3 dan studi Hellenic Cooperative Oncology Group (HeCOG). ICON3 menunjukkan bahwa agen tunggal carboplatin dan CAP sama efektif dengan paclitaxel plus carboplatin sebagai pengobatan lini pertama pada penderita kanker ovarium yang membutuhkan kemoterapi. ${ }^{9}$ Pada tahun 2008, studi HeCOG membandingkan regimen kemoterapi cisplatin, paclitaxel, dan doxorubicin (kelompok antrasiklin) dengan carboplatin dan paclitaxel yang merupakan kemoterapi lini pertama standar terstandar pada kanker ovarium stadium lanjut. ${ }^{8}$ Status perfoma lebih baik pada kelompok antrasiklin. Dalam hal toksisitas, perbedaan utama antara kedua kelompok tersebut adalah munculnya neutropenia febril pada kelompok antrasiklin. Dengan median follow-up selama 57,7 bulan, terdapat perbaikan marginal pada progression- free survival (PFS) di kelompok antrasiklin walaupun tidak terdapat perbedaan signifikan pada angka ketahanan hidup. ${ }^{8}$

Dengan prognosis yang tidak berbeda antara regimen PCdanCAPterhadapangka ketahanan hidup, regimen kemoterapi CAP dapat dipertimbangkan sebagai regimen kemoterapi lini pertama dalam terapi kanker ovarium. Menurut sebuah studi retrospektif di multisenter yang menggunakan cyclophosphamide oral metronomik, CAP dinilai dapat menjadi alternatif dalam pengobatan paliatif pada pasien kanker ovarium rekuren. ${ }^{10}$ Keuntungan utama dari regimen CAP adalah efektif dalam menurunkan aktivitas tumor, dapat digunakan dalam setting rawat jalan, harga yang lebih murah, dan profil toksisitas yang rendah. ${ }^{11}$

Berdasarkan hasil analisis multivariat yang dilakukan, terdapat 2 faktor risiko yang dapat memengaruhi angka ketahanan hidup yaitu stadium dan CA125 pasca kemoterapi. Stadium diketahui merupakan faktor prognostik yang kuat terhadap angka ketahanan hidup. Penelitian kami dengan analisis multivariat menunjukkan bahwa pasien dengan stadium awal secara statistik menurunkan angka mortalitas sebesar 0,45 kali dibandingkan stadium lanjut dengan $\mathrm{p}<0,05$. Hal ini sesuai dengan Berek dan Hillard, 2012 yang menunjukkan bahwa angka ketahanan hidup 5 tahun pada stadium 1 adalah $90 \%$ dan stadium II adalah 60\%. Angka ketahanan hidup menurun pada stadium lanjut (III dan IV) yaitu sekitar $30 \% .{ }^{12}$

\section{KESIMPULAN DAN SARAN}

Pengobatan kanker ovarium masih menjadi tantangan bagi ahli onkologi karena frekuensi yang tinggi pada penyakit stadium lanjut saat terdiagnosis dan kurangnya pendekatan pengobatan sistemik yang lebih baik. Penggunaan regimen kemoterapi yang lama dapat menjadi strategi yang efektif untuk memberi pilihan terapeutik yang lebih banyak kepada pasien.

Kesimpulan dari penelitian ini adalah regimen PC memiliki risiko kematian sebesar 1,15 kali dibandingkan dengan regimen CAP, dengan nilai $\mathrm{p}$ yang tidak signifikan terhadap angka ketahanan hidup penderita kanker ovarium yang dirawat di RSUP dr. Sardjito selama tahun 2014-2018. Dengan prognosis yang tidak berbeda antara regimen PC dan CAP terhadap angka ketahanan hidup dan harga CAP yang lebih murah daripada $\mathrm{PC}$, regimen kemoterapi CAP dapat dipertimbangkan sebagai regimen kemoterapi lini pertama dalam terapi kanker ovarium di RSUP dr. Sardjito.

Faktor-faktor yang dapat meningkatkan angka ketahanan hidup pasien kanker ovarium adalah stadium klinis awal dan CA125 pasca kemoterapi $<70 \mathrm{~mL}$.

\section{DAFTAR PUSTAKA}

1. Colombo, N., Peiretti, M., Parma, G., Lapresa, M., Mancari, R., Carinelli, S., Sessa, C. and Castiglione, M. Clinical Practice Guidelines Newly Diagnosed and Relapsed Epithelial Ovarian Carcinoma: ESMO Clinical Practice Guidelines for Diagnosis, Treatment and Follow-up Clinical Practice Guidelines. Annals 
of Oncology. doi: 10.1093/annonc/mdq244. 2010; 21(Supplement 5): 23-30.

2. Baldwin, L. A., Huang, B., Miller, R. W., Tucker, T., Goodrich, S. T., Podzielinski, I., Desimone, C. P. and Ueland, F. R. Ten-Year Relative Survival for Epithelial Ovarian Cancer. Obstetrics \& Gynecology. 2012; 120(3): 612-618

3. Devita, V. T., Rosenberg, S. A., Paget, S. and Avery, O. Two Hundred Years of Cancer Research. The New England Journal of Medicine. 2012: 2207- 2214

4. Morgan, R. J., Armstrong, D. K., Alvarez, R. D., Bakkum-gamez, J. N., Behbakht, K., Chen, L., Copeland, L., Crispens, M. A., Derosa, M., Dorigo, O., Gershenson, D. M., Gray, H. J., Hakam, A., Havrilesky, L. J., Johnston, C., Lele, S., Martin, L., Penson, R. T., Percac-lima, S., Pineda, M., Plaxe, S. C., Powell, M. A., Ratner, E., Remmenga, S. W., Rose, P. G., Sabbatini, P., Santoso, J. T., Werner, T.L. and Burns, J. Ovarian Cancer, Clinical Practice Guidelines in Oncology. Journal of the National Comprehensive Cancer Network. 2016; 14(9): 1134-1163

5. Ahyar, I., Rachman, I. T. and Kusumanto, A. Regimen Paclitaxel dan Carboplatin dengan Regimen Cyclophosphamide, Adriamycin dan Cisplatin. Jurnal Kesehatan Reproduksi. 2017; 4(1): 1-10

6. Kurnianda, J., Widayati, K., Purwanto, I., Hardianti, M. S. and Wulanningsih, W. Buku Protokol Kemoterapi: Pedoman Tatalaksana Terapi Sistemik pada Kanker. 2011

7. Giannopoulos, T., Butler-Manuel, S., Taylor, A., Ngeh, N. and Thomas, H. Clinical Outcomes of Neoadjuvant Chemotherapy and Primary Debulking Surgery in Advanced Ovarian Carcinoma. European Journal of Gynaecological Oncology. 2006; 27(1): 25-28
8. Aravantinos, G., Fountzilas, G., Bamias, A., Grimani, I., Rizos, S., Kalofonos, H.P., Skarlos, D.V., Economopoulos, T., Kosmidis, P.A., Stathopoulos, G.P. and Briasoulis, E. Carboplatin and paclitaxel versus cisplatin, paclitaxel and doxorubicin for firstline chemotherapy of advanced ovarian cancer: a Hellenic Cooperative Oncology Group (HeCOG) study. European Journal of Cancer. 2008; 44(15): 2169-2177.

9. Tortorella, L., Vizzielli, G., Fusco, D., Cho, W. C., Bernabei, R., Scambia, G., \& Colloca, G. Ovarian Cancer Management in the Oldest Old: Improving Outcomes and Tailoring Treatments. 2017; 8(5): 677-684

10. The International Collaborative Ovarian Neoplasm (ICON) Group, T. I. C. O. N. (ICON) G. Paclitaxel Plus Carboplatin Versus Standard Chemotherapy with either Single-Agent Carboplatin or Cyclophosphamide, Doxorubicin, and Cisplatin in Women with Ovarian Cancer: The ICON3 Randomised Trial. Lancet. 2002; 360: 505-515

11. Ferrandina, G., Corrado, G., Mascilini, F., Malaguti, P., Samaritani, R., Distefano, M., Masciullo, V., Di Legge, A., Savarese, A. and Scambia, G. Metronomic oral cyclophosphamide (MOC) in the salvage therapy of heavily treated recurrent ovarian cancer patients: a retrospective, multicenter study. BMC cancer. 2014; 14(1): 947

12. de Boo, L.W., Vulink, A.J.E. and Bos, M.E.M.M. Metronomic cyclophosphamide-induced long-term remission after recurrent high-grade serous ovarian cancer: A case study. Molecular and clinical oncology. 2017; 7(6): 1130-1134

13. Berek, J. S. and Hillard, P. J. A. Initial Assessment and Communication', in Berek and Novak's Gynecology. 15th Ed. Lippincott Williams and Wilkins. 2012 